\section{The frustration effect as a function of interoceptive and exteroceptive cues in a Skinner box analogue of the double runway*}

\author{
MARK COLE and FREDERICK $M$. VAN FLEET \\ University of Western Ontario, London, Ont., Canada
}

In a Skinner-box analogue of the double runway, rats which received more exposure to interoceptive or exteroceptive cues failed to show a greater FE than a control group. In addition, no evidence was found for a depression in response rate following reinforcement or for facilitation in response rate following nonreinforcement due to frustration. The results were discussed in terms of Amsel's theory of frustrative nonreinforcement and incentive contrast.

Amsel, Ernhart, \& Galbrecht (1961) found that the frustration effect (FE) measured in Runway 2 of a double runway was larger when Runway 1 was long than when it was short. Amsel explained this result by assuming that in the first alley, Ss received more exposure to both interoceptive- and exteroceptive-produced $I_{G}$ cues.

Using a Skinner-box analogue of the double runway, it should be possible to separate interoceptive- and exteroceptive-produced $r_{G}$ cues and test the effect of each on the FE.

Wagner (1959) has shown that a proper control for the possible depressive effects of reward is necessary for proper interpretation of the FE. Similarly, Hamm \& Zimmerman (1967) have pointed out the importance of controlling for response facilitation following nonreinforcement due to incentive contrast effects. Both these comparisons are necessary in order to demonstrate facilitation attributable to an emotional factor such as frustration.

\section{EXPERIMENT 1}

\section{Subjects}

Twelve female albino rats, 120 days old at the start of the experiment, served as Ss and were maintained at $80 \%$ of their free-feeding body weights.

\section{Apparatus}

A Lehigh Valley Skinner box (Model 1417) with dual retractable levers and a liquid dipper that dispensed $0.1 \mathrm{ml}$ of a $21 \%$ (by weight) solution of Nestlés sweetened condensed milk in water was used. A frosted cue light was located over each lever and was illuminated whenever

\footnotetext{
*This study is based on a Master's thesis (Cole, 1969) and was supported in part by a National Research Council of Canada grant, APA 286, to the second author, and a grant from the University of Western Ontario Research Fund. Grateful acknowledgment is due Drs. H. O. Lobb and $D$. Pederson for their valuable criticism in the planning and execution of the research and the writing of the mant script.
}

the lever beneath it was accessible to $S$. The box was enclosed in a sound-insulated, separate room from the programming equipment. All latencies and response times were recorded on running time meters, and all E-controlled events were operated by standard programming equipment.

\section{Method}

Following magazine training, a lever-pressing response was shaped to the left and right levers. Reinforcement consisted of a 4-sec access to the dipper. Ss were then assigned randomly to one of four groups $(\mathrm{N}=3)$. A control group (Group C) was placed on a MULT (FR10-FR10) schedule of reinforcement in which 10 responses were required on each lever for reinforcement, the levers alternating regularly. One experimental group (Group EXT) was also placed on a MULT (FR10-FR10) schedule of reinforcement in which a series of exteroceptive cues were summated throughout the schedule on Lever 1 and correlated with reinforcement (i.e., the 4 th response initiated white noise composed of frequencies ranging from $115 \mathrm{~Hz}$ to $15 \mathrm{KHz}$; the 7 th response initiated a tone of $420 \mathrm{~Hz}$; the 10th response illuminated an 8.5-W houselight; the combined loudness of the white noise plus tone was measured at $71 \mathrm{~dB}$, while the measured illumination of the houselight plus the left cue light was $21.9 \mathrm{fc}$ ). These stimuli terminated with the withdrawal of the dipper. It was postulated that this procedure should increase exposure to exteroceptive-produced $\mathrm{r}_{\mathrm{G}}$ cues relative to Group C without significantly increasing interoceptive-produced cues. A second experimental group (Group L) was placed on a MULT (FR25-FR10) schedule in which 25 responses were required on Lever 1 for reinforcement. It was postulated that this group should receive greater exposure to interoceptive-produced ventilated chamber and was located in a
${ } \mathrm{G}$ cues relative to Group $\mathrm{C}$ without significantly increasing exposure to exteroceptive-produced cues. A continuously nonreinforced group (Group CNR) was placed on a CHAIN (FR10-FR10) schedule in which responding on Lever 1 was never reinforced. For all groups in this study, a trial was defined as the successive presentation of Levers 1 and 2 , and each $S$ received 20 trials per day. The interlever interval was $6 \mathrm{sec}$ long and the intertrial interval was variable (mean $=30 \mathrm{sec})$ within a range of 15 to $45 \mathrm{sec}$ for all Ss.

After 60 days, when all Ss were responding in a stable fashion on their respective schedules, frustration training was begun for Groups C, L, and EXT. During each session, a random half of the reinforcers on Lever 1 were omitted. Four dependent measures were recorded daily for each $S$ as follows: (1) cumulative latency on Lever 2 following reinforcement (R) on Lever 1 ; (2) cumulative latency on Lever 2 following nonreinforcement (NR) on Lever 1; (3) cumulative response time on Lever 2 following $R$ on Lever 1 ; and (4) cumulative response time on Lever 2 following NR on Lever 1 . In this study, the latency measure was the time from the start of lever insertion until the first response, while the response time measure was the time from the 1 st response until the 10th. Both latencies and response times were cumulated over 18 trials for each $S$ (the first two trials in each session were not recorded to allow for warm-up effects). Since latencies and response times tend to be positively skewed (Winer, 1962), these data were converted to logarithms. Frustration training was continued for 10 days, at which time the experiment was terminated.

Results and Discussion

The response time data recorded from Lever 2 are presented in Fig. 1. Each bar represents a mean log cumulative response time representing the data for the three Ss in each group over 10 days. Although the data for individual Ss are not included, they closely resemble the group means. The figure shows that while the difference between $R$ and $N R$ response times for Group CNR seems negligible, Groups C, L, and EXT all appear to have responded faster following NR than following $R$.

These differences were tested for significance by means of a two-way analysis of variance (Winer, 1962). A similar analysis was performed on the latency data, which do not appear in Fig. 1. The "cue factor" in both analyses was a between-Ss factor with four levels $(C$, L, EXT, and CNR), while the "R-NR factor" was a within-Ss factor with two levels ( $R$ trials and NR trials). Although the 


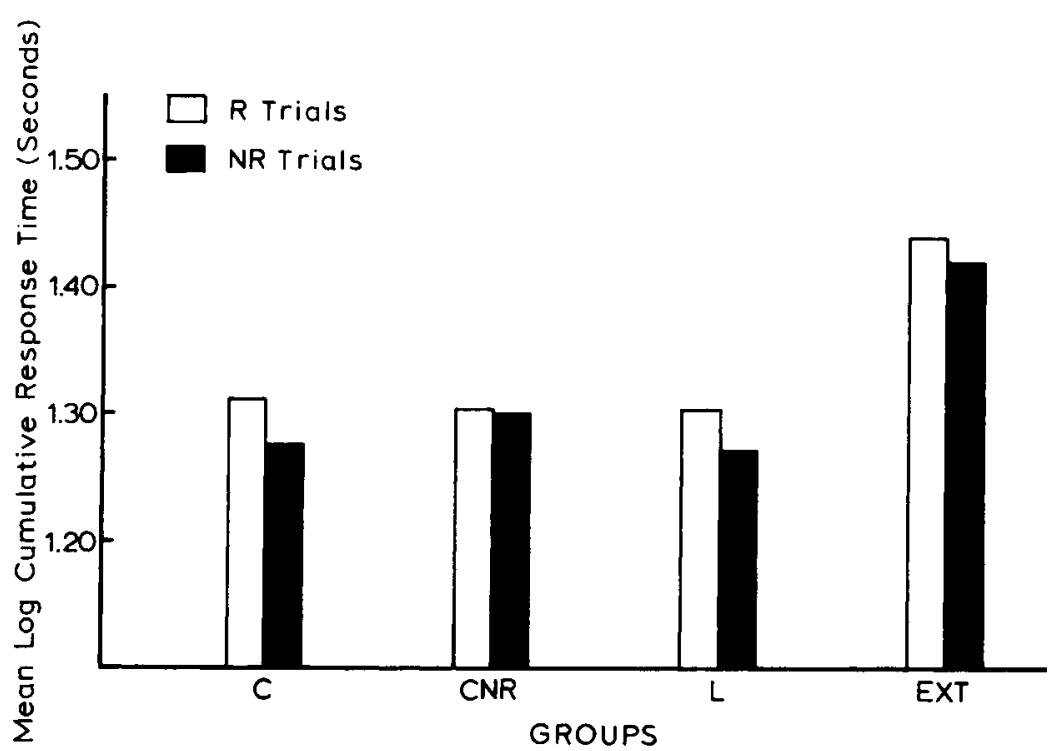

latency data produced no significant results, the response time measure yielded a significant R.NR factor $(F=9.814$; $\alpha=.05 ; \mathrm{df}=1,8)$. These differences were interpreted as demonstrating an overall frustration effect (i.e., Ss, irrespective of group, responded faster following NR than R). Unfortunately, however, the lack of a significant Cue by R-NR interaction precluded the possibility of showing that the FE for Group L was greater than that for Group C. In summary, there was no evidence that the FE for either Group L or EXT, or both, was greater than that of Group C. As a result, the data fail to support the interpretation of Amsel et al (1961) with regard to the role of $\mathrm{r}_{\mathrm{G}}$.

A between-groups post hoc analysis (cf. Hays, 1963) showed that Group C did not respond more slowly following reinforcement than did Group CNR following chronic nonreinforcement, thus offering no support for the hypothesis that reinforcement produces a decrement in response rate. A similar comparison showed that Group C did not respond faster following nonreinforcement than did Group CNR following chronic nonreinforcement. This latter finding was in accord with the results of Hamm \& Zimmerman (1967) and offers no evidence for response facilitation over and above that which might be attributed to incentive contrast. An emotional-arousal explanation would thus appear to be unparsimonious. It should be noted, however, that due to the small number of $\mathrm{Ss}$ in each group $(\mathrm{N}=3)$, the between-Ss variance ( $\sigma=.0031)$ is quite large compared to the within-Ss variance $(\sigma=.0003)$. As a result, the FE, which is a within-Ss measure, is probably more meaningful than the between-Ss comparisons suggested by Wagner (1959) and Hamm \& Zimmerman
Fig. 1. Mean log cumulative response time on Lever 2 as a function of cue group (C, L, EXT, and CNR) and $R$ or NR on Lever 1. Experiment 1.

\section{Method}

The experimental paradigm used was similar to that employed in Experiment 1. A control group (Group C) was placed on a MULT (FR10-FR10) schedule of reinforcement in which 10 responses were required on each lever for reinforcement, the levers alternating regularly. An experimental group (Group EXT) was also placed on a MULT (FR10-FR10) schedule of reinforcement but various exteroceptive cues were summated throughout the schedule on Lever 1 and correlated with reinforcement (i.e., the 4th response illuminated the frosted cue light over the left lever; the 7 th response initiated a tone of $420 \mathrm{~Hz}$; the 10th response illuminated an $8.5-\mathrm{W}$ houselight; the loudness of the tone was measured at $70 \mathrm{~dB}$, while the combined illumination of the cue light plus the houselight was $21.9 \mathrm{fc}$ ). These stimuli terminated with the withdrawal of the dipper. The white-noise cue was omitted in this study to avoid masking of the tone. The cue light, present for all groups in the previous study, was utilized in this study only for Group EXT in a further attempt to reduce the number of exteroceptive cues for all groups except EXT. A second experimental group (Group L) was placed on a MULT (FR50-FR25) schedule, in which 50 responses were required on Lever 1 for reinforcement. In the previous study, this group had been on a MULT (FR25-FR10) schedule which probably yielded fewer interoceptive-produced $I_{G}$ cues. A continuously nonreinforced group (Group CNR), was placed on a CHAIN (FR10-FR10) schedule in which responding on Lever 1 was never reinforced. In this experiment, preliminary training was continued for only 20 days, at which time the cumulative records showed that responding was stable. Otherwise the training and recording procedures were identical to those used in the first experiment.

\section{Results and Discussion}

The response-time data recorded from Lever 2 are presented in Fig. 2. Each bar represents a mean log cumulative response time representing the data for the three Ss in each group over 10 days. Once again, the data for individual Ss closely resembled the group data and hence are not included. Figure 2 shows, as predicted, almost no difference between the mean $\log$ cumulative response times recorded during $R$ and NR trials for Group CNR. Groups C, $\mathrm{L}$, and EXT, however, all appear to have 


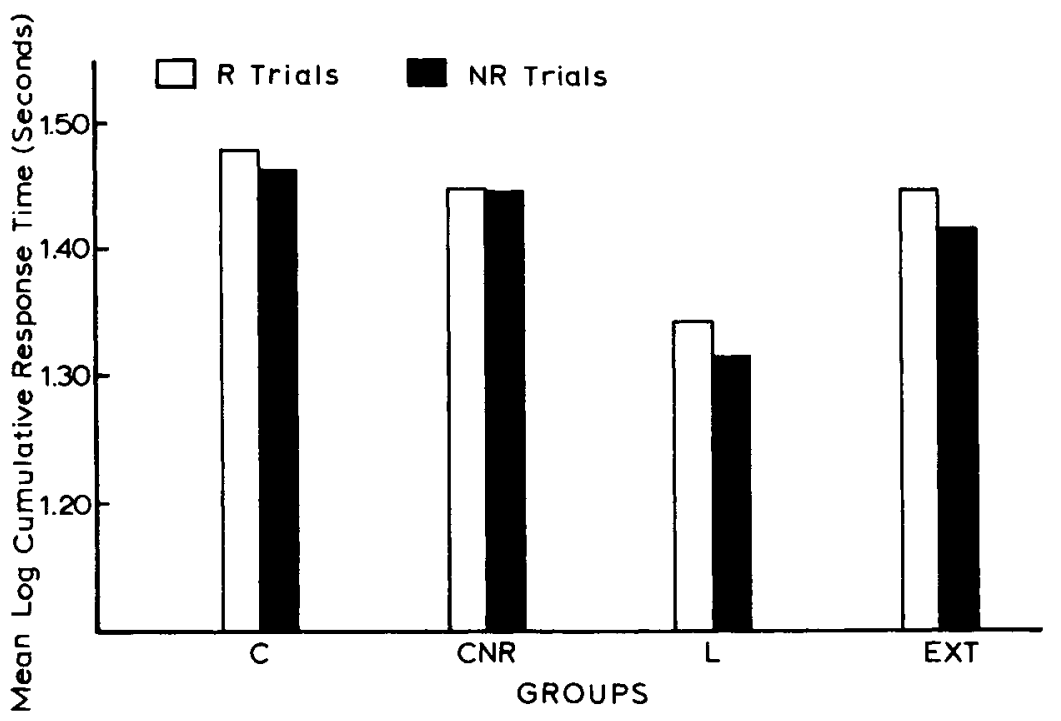

responded faster following NR than between-Ss post-hoc comparison (cf. Hays, following $\mathrm{R}$.

These differences were tested for significance by means of a two-way analysis of variance (Winer, 1962). A similar analysis was performed on the latency measures, which are not represented in Fig. 2. The "cue factor" in both analyses was a between-Ss factor with four levels (C, L, EXT, and CNR), while the "R-NR" factor was a within-Ss factor with two levels ( $R$ trials and NR trials). Although the latency data produced no significant results, the response time measure yielded a significant R-NR factor $(F=13.043 ; \alpha=.05 ; d f=1,8)$. This can be interpreted to mean that $S$, irrespective of group, responded faster following NR than R (i.e., showed a significant FE). Unfortunately, the lack of a significant Cue by R-NR interaction again precluded any attempt to demonstrate that the FE for Groups $L$ and EXT was greater than that for Group C.

It is evident from Fig. 2 that Group C did not respond faster following nonreinforcement than did GroupCNR following chronic nonreinforcement (the results lie in the opposite direction). As a result there is no evidence for a facilitative effect due to nonreinforcement attributable to an emotional factor such as "frustration." In addition, however, a
Fig. 2. Mean log cumulative response time on Lever 2 as a function of cue group (C, L, EXT, and CNR) and R or NR on Lever 1. Experiment 2.

one failed to find any FEs in the latency data. This is not in agreement with the findings of other investigators using the Skinner box (i.e., Davenport \& Thompson, 1965; Carlson, 1968) who found shorter latencies following NR than following $R$. It should be noted, however, that the appearance of an FE in latency measures can be explained in terms of the pause after reinforcement (PAR). Felton \& Lyon (1966) showed that a reliable PAR follows reinforcement on an FR schedule. Longer latencies might thus be expected following $\mathbf{R}$ trials in a frustration paradigm, which could be explained without resorting to frustration theory. The lack of any FEs in the latency data in the present study as well as the previous one might be due to the fact that the PAR occurred during the interlever interval. respond more slowly following reinforcement than did GroupCNR following chronic nonreinforcement. Thus, there is no evidence for a decrease in response rate as a function of reinforcement. Both these results agree with those of the previous study. The between-Ss variance $(\sigma=.0023)$ was again larger than the within-Ss variance $(\sigma=.0002)$, suggesting that caution should be used in interpreting the between-groups comparisons. It was reassuring to note, however, that the proportion of variance accounted for by the R-NR factor was .47 (Winer, 1962).

\section{DISCUSSION}

The results of these studies fail to support Amsel's theory with regard to the role of $\mathrm{r}_{\mathrm{G}}$. Two reasons for this failure might be the small $\mathrm{N}$ employed and a ceiling effect obtained on the ratio schedules. As FR schedules typically generate high rates of responding, further increases in rate following nonreinforcement might be impossible due to the physiological limitations of the organism. Increasing the $\mathrm{N}$ in future studies would tend to reduce between-S variance and thus would increase the probability of obtaining a Group by R-NR interaction.

Both the present study and the previous

\section{REFERENCES}

AMSEL, A., ERNHART, C. B., \& GALBRECHT, C. R. Magnitude of frustration and strength of antedating goal factors. Psychological Reports, $1961,8,183-186$.

CARLSON, J. G. Frustrative non-reinforcement of operant responding: Magnitude of reinforcement and response force effects. Psychonomic Science, 1968, 11, 307-308.

COLE, M. The frustration effect as a function of interoceptive and exteroceptive cues in a Skinner box analogue of the double runway. Unpublished Master's thesis, The University of Western Ontario, London, Ont., Canada, 1969.

DAVENPORT, J. W., \& THOMPSON, C. I. The Amsel frustration effect in monkeys. Psychonomic Science, 1965, 3, 481-482.

FELTON, M., \& LYON, D. O. The post-reinforcement pause. Journal of the Experimental Analysis of Behavior, 1966, 9, 131-134.

HAMM, H. D., \& ZIMMERMAN, J. A "frustration effect" in operant studies: A necessary control procedure. Psychonomic Science, 1967, 9, 253-254.

HAYS, W. L. Statistics for psychologists New York: Holt, Rinehart \& Winston, 1963.

WAGNER, A. R. The role of reinforcement and nonreinforcement in an "apparent frustration effect." Journal of Experimental Psychology, $1959,57,130-136$.

WINER, B. J. Statistical principles in experimental design. New York: McGraw-Hill, 1962. 